\title{
8
}
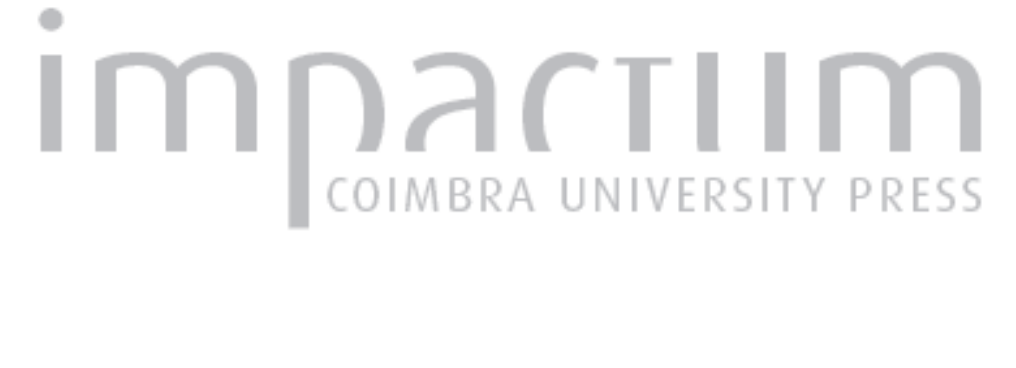

\section{Risco de inundações urbanas em Mirandela e o ordenamento do seu território como forma de prevenção}

Autor(es): $\quad$ Gouveia, Maria; Lourenço, Luciano

Publicado por: $\begin{aligned} & \text { Associação Portuguesa de Riscos, Prevenção e Segurança; Imprensa } \\ & \text { da Universidade de Coimbra }\end{aligned}$

URL

persistente:

DOI: DOI:https://doi.org/10.14195/1647-7723_24_18

Accessed : $\quad$ 26-Apr-2023 10:31:29

A navegação consulta e descarregamento dos títulos inseridos nas Bibliotecas Digitais UC Digitalis, UC Pombalina e UC Impactum, pressupõem a aceitação plena e sem reservas dos Termos e Condições de Uso destas Bibliotecas Digitais, disponíveis em https://digitalis.uc.pt/pt-pt/termos.

Conforme exposto nos referidos Termos e Condições de Uso, o descarregamento de títulos de acesso restrito requer uma licença válida de autorização devendo o utilizador aceder ao(s) documento(s) a partir de um endereço de IP da instituição detentora da supramencionada licença.

Ao utilizador é apenas permitido o descarregamento para uso pessoal, pelo que o emprego do(s) título(s) descarregado(s) para outro fim, designadamente comercial, carece de autorização do respetivo autor ou editor da obra.

Na medida em que todas as obras da UC Digitalis se encontram protegidas pelo Código do Direito de Autor e Direitos Conexos e demais legislação aplicável, toda a cópia, parcial ou total, deste documento, nos casos em que é legalmente admitida, deverá conter ou fazer-se acompanhar por este aviso. 


\section{MULTIDISCIPLINARIDADE NA ANÁLISE DAS MANIFESTAÇÕES DE RISCO}

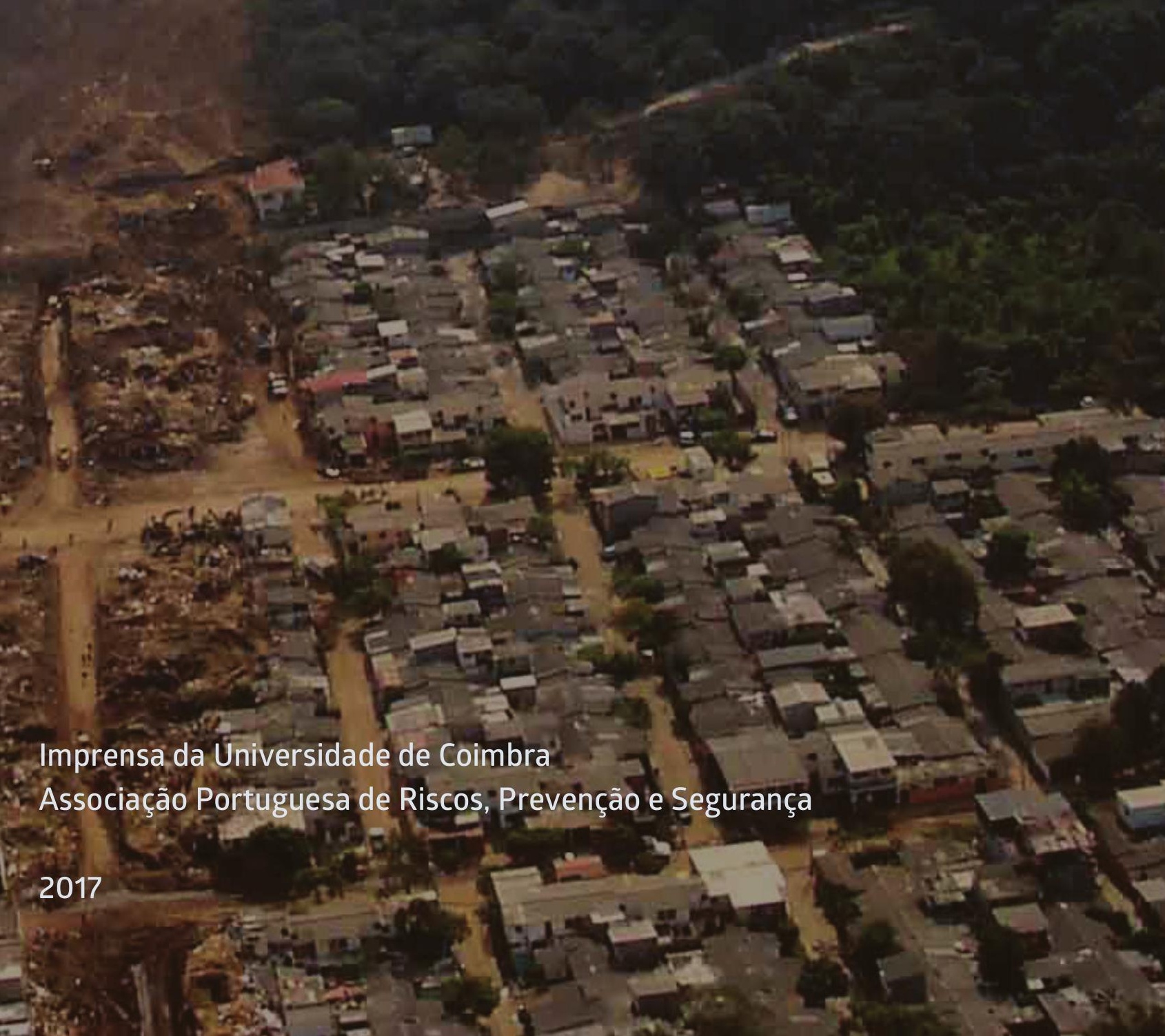


Maria Gouveia

Departamento de Geografia e Turismo e CEGOT Faculdade de Letras da Universidade de Coimbra mmalgouveia@gmail.com

Luciano Lourenço

Departamento de Geografia e Turismo e CEGOT Faculdade de Letras da Universidade de Coimbra luciano@uc.pt

\section{RESUMO}

A ocorrência de inundações na cidade de Mirandela é um fator condicionante da vida dos cidadãos que aí residem, trabalham ou lá se deslocam para a visitar. Para melhor conhecer este risco, decidiu-se estudar a influência do processo de urbanização na manifestação das cheias e consequentes inundações. Pretende-se, assim, contribuir para uma mais eficaz proteção de pessoas, animais e bens patrimoniais.

Palavras-chave: Inundação urbana, ordenamento do território, Mirandela.

\section{ABSTRACT}

The occurrence of floods in Mirandela is determinant for the lives of the citizens who are living, working or visiting the city. So, to better understand this risk, we decided to study the influence of the urbanization process in the event of floods and consequent flooding. This is intended to contribute to the more effective protection of people, animals and heritage assets.

Keywords: Urban flooding, territory management, Mirandela.

\section{Introdução}

Sabendo-se que a subida do nível da água do rio Tua provoca, por vezes, inundações na cidade de Mirandela e que estas são um fator condicionante da vida dos cidadãos que aí residem, trabalham ou lá se deslocam para a visitar, decidiu-se estudar a manifestação deste fenómeno.

A caraterização dos fatores de escoamento da cidade de Mirandela e da área envolvente (desde a Foz do rio Tua até às províncias espanholas de Ourense e Zamora), bem como a análise histórica das inundações, o estudo do processo de urbanização e das condicionantes ao escoamento superficial (C. Ramos, 2009, p. 75; DGRAH, 1984, pp. 519-529) e, por último, o cálculo do risco de inundação, permitem um melhor conhecimento das condições em que o fenómeno ocorre e o modo como este se manifesta. Partindo desta informação, o objetivo deste estudo visa perspetivar o futuro de ocorrência de inundações (Deltares, 2010, pp. 17-27) na cidade de Mirandela através da criação de cenários, podendo, assim, serem definidas medidas de mitigação para a redução dos efeitos nefastos que elas provocam.

A metodologia passa por caraterizar o processo de urbanização, através da análise da variação do número de edifícios e de habitantes residentes na cidade de Mirandela, bem como da cartografia das áreas impermeabilizadas em diferentes momentos temporais, podendo assim aferir-se o modo como esse processo tem vindo a ser efetuado.

Assim, no presente estudo considerou-se que o processo de urbanização na cidade de Mirandela está relacionado com o número de edifícios e de habitantes residentes na cidade, bem como com a evolução das áreas impermeabilizadas.

A variação do número de edifícios e de habitantes que residem em Mirandela é analisada com base nos dados e na cartografia que o Instituto Nacional de Estatística

* O texto desta nota foi submetido em 15-09-216, sujeito a revisão por pares a 30-09-0000 e aceite para publicação em 25-11-2016. Esta nota é parte integrante da Revista Territorium, n. ${ }^{\circ} 24,2017,{ }^{\circ}$ RIscos, ISSN: 0872-8941. 
(INE) disponibiliza, nomeadamente o número de edifícios e de habitantes por subsecção estatística nos anos de 1991, 2001 e 2011. Essa análise é feita para a totalidade do concelho e para a freguesia de Mirandela, bem como para a área de estudo que foi delimitada com base em caraterísticas físicas do terreno, tais como estradas ou margens de cursos de água, tendo em conta a espacialização da ocorrência de inundações desde o ano de 1909. Com base em notícias publicadas em jornais locais, regionais ou nacionais, é possível mencionar a ocorrência de inundações na cidade de Mirandela, pelo menos nas seguintes datas: século XV, 1860, 1889,1909, 1937,1939, 1958, 1959, 1960, 1962, 1963, 1966, 1969, 1972, 1987, 1995, 1996, 2000, 2001 e 2012.

A delimitação da área impermeabilizada, na área de estudo, foi aferida com base na configuração da área urbana existente em diferentes momentos temporais, tendo-se optado como base de trabalho, em função dos meios cartográficos disponíveis, pela cartografia em formato raster, dos anos de 1980 e de 2012, podendo, assim, conhecer-se a evolução da área impermeabilizada ao longo de mais de trinta anos.

A relação entre o risco de inundação com aspetos de ordenamento do território já foi alvo de muitos estudos, como por exemplo, no estudo de F. Costa (2009, pp. 99-111), bem como de produção de legislação com diferentes níveis territoriais, nomeadamente europeu, nacional, regional e local. Exemplo desta situação é a transposição para a ordem jurídica nacional da Diretiva Europeia n. ${ }^{\circ} 2007 / 60 / C E$, de 23 de outubro, para o Decreto-Lei n. ${ }^{\circ} 115 / 2010$, de 22 de outubro.

A legislação existente é rica e abundante e visa a mitigação do risco através da indicação de obrigatoriedade de elaboração de um historial de inundações e suas consequências; de cartografia de áreas sujeitas a inundações; de planos especiais de emergência; de cartografia de risco e; entre outras, da criação de cenários de inundações. No entanto, a aplicação da lei não tem sido muito favorável pois continuam a verificar-se inundações cuja causa se deve ao inadequado ordenamento do território, consequente da não aplicação de regras que minimizam ou superam a manifestação nefasta de uma cheia. São vários os autores que se debruçam sobre esta temática, sendo os seus contributos valiosíssimos para a melhoria das condições de vida da população.

Os estudos até então realizados demonstram que existem vários métodos de cálculo do risco de inundação e também diferem quanto às variáveis que se devem considerar. No entanto, apesar de algumas controvérsias, todos os autores concordam com o facto de que o estudo do risco de inundação tem de ser considerado e integrado em todos os procedimentos relacionados com o ordenamento do território, devendo ser calculado por equipas multidisciplinares.

\section{Processo de urbanização na cidade de Mirandela}

Variação do número de edifícios e de habitantes que residem em Mirandela

A população residente no concelho de Mirandela, durante os 30 anos que separam 1981 de 2011, teve algumas oscilações, uma vez que na primeira década, entre 1981 e 1991, se verificou um decréscimo de 3670 habitantes que, em parte, foi compensado nos dez anos seguintes, quando se registou um aumento de 610 habitantes. Mais tarde, entre 2001 e 2011 verificou-se, novamente, um decréscimo da população residente, na ordem dos 1969 habitantes. Assim, a população que residia no concelho de Mirandela entre 1981 e 2011, sofreu um decréscimo de 17,4\% (fig. 1-A). Quanto ao edificado, verificou-se que, entre 1981 e 2011, o concelho de Mirandela registou um constante crescimento (fig. 1-B), sendo a variação positiva, na ordem dos $27,6 \%$, o que corresponde a um acréscimo de 2497 edifícios em 30 anos.

Por sua vez, entre 1991 e 2011, a freguesia de Mirandela registou um contínuo crescimento da população, ao contrário do observado no concelho de Mirandela, sendo a taxa de variação de 44,7\% (fig. 2-A). Esta situação
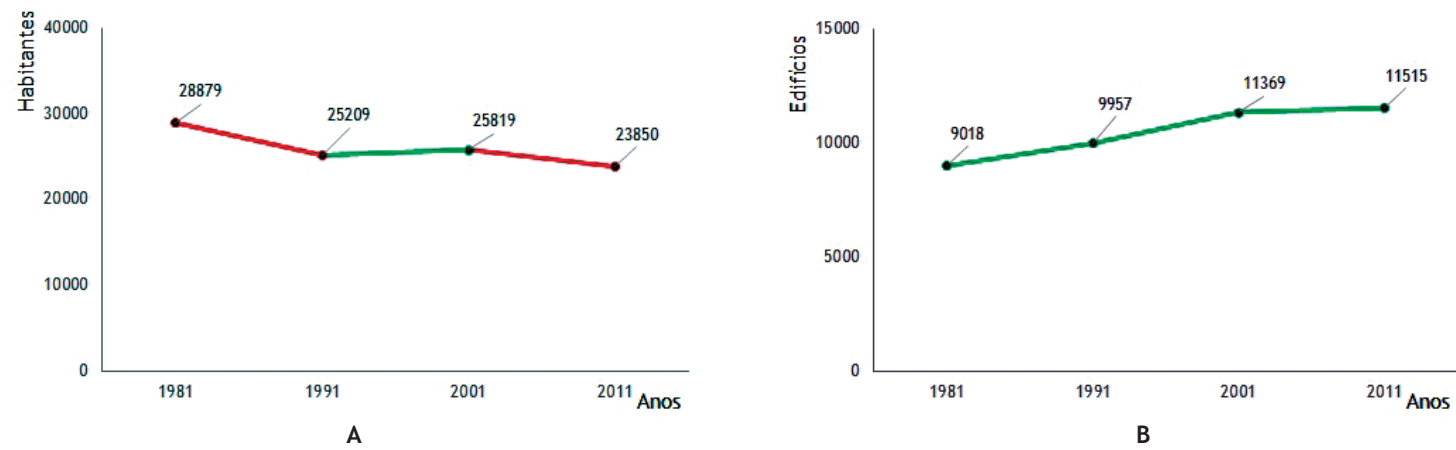

Fig. 1 - População residente (A) e número de edifícios (B) do concelho de Mirandela (Fonte dos dados: INE, 1981, 1991, 2001, 2011).

Fig. 1 - Resident population (A) and buildings (B) in Mirandela county (Data source: INE, 1981, 1991, 2001, 2011). 
deve-se ao facto de a freguesia sede do concelho ser um polo funcional atrativo para as restantes freguesias do concelho, bem como para as localidades dos concelhos adjacentes que lhe são mais próximas. De facto, é na cidade e freguesia de Mirandela que se concentram as atividades industrial (sobretudo na zona industrial) e comercial, havendo, por exemplo, uma grande concentração de cafés, restaurantes, lojas de eletrodomésticos, de roupa e supermercados. É aí que também se concentram os serviços, desde vários serviços camarários, aos da Santa Casa da Misericórdia, Tribunal, Polícia de Segurança Pública, Guarda Nacional Republicana, Escolas, entre outros. Por isso, não admira que nos 20 anos que separam

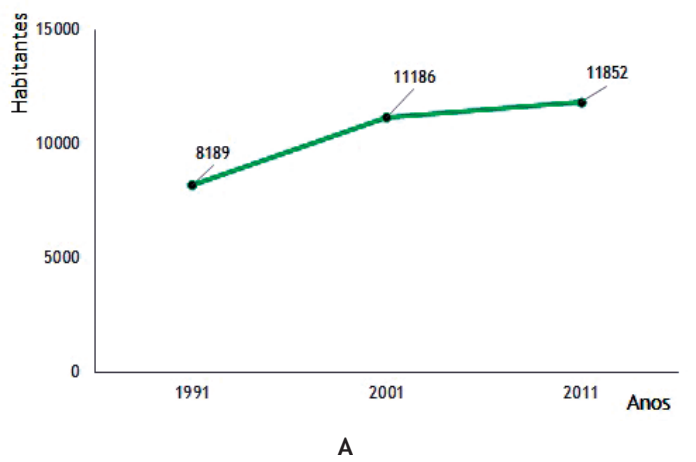

1991 de 2011, também se tenha registado um contínuo crescimento de edifícios, sendo a variação na ordem dos $60,3 \%$, valor que corresponde, em termos absolutos, a um acréscimo de 1121 edifícios (fig. 2-B).

A área de estudo possui $1,65 \mathrm{~km}^{2}$ e compreende dois espaços descontínuos (fig. 3), sendo o que se localiza mais a norte correspondente à área onde se estabeleceu o Parque de Campismo "Três Rios Maravilha". O outro, situa-se em plena cidade e acompanha os traçados do rio Tua e da ribeira de Carvalhais, desde o Parque Dr. José Gama até ao parque de merendas e desde o acesso Norte à Autoestrada 4 até à foz da ribeira de Carvalhais, respetivamente.

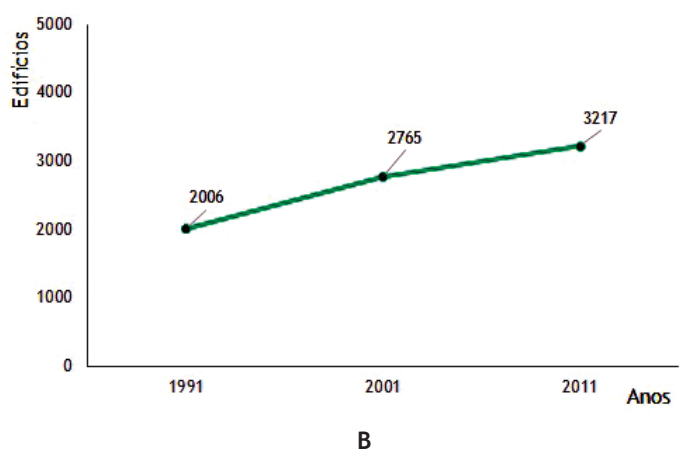

Fig. 2 - População residente (A) e número de edifícios (B) na freguesia de Mirandela (Fonte dos dados: INE, 1991, 2001, 2011).

Fig. 2 - Resident population (B) and buildings (B) in Mirandela parish (Data source: INE, 1991, 2001, 2011).

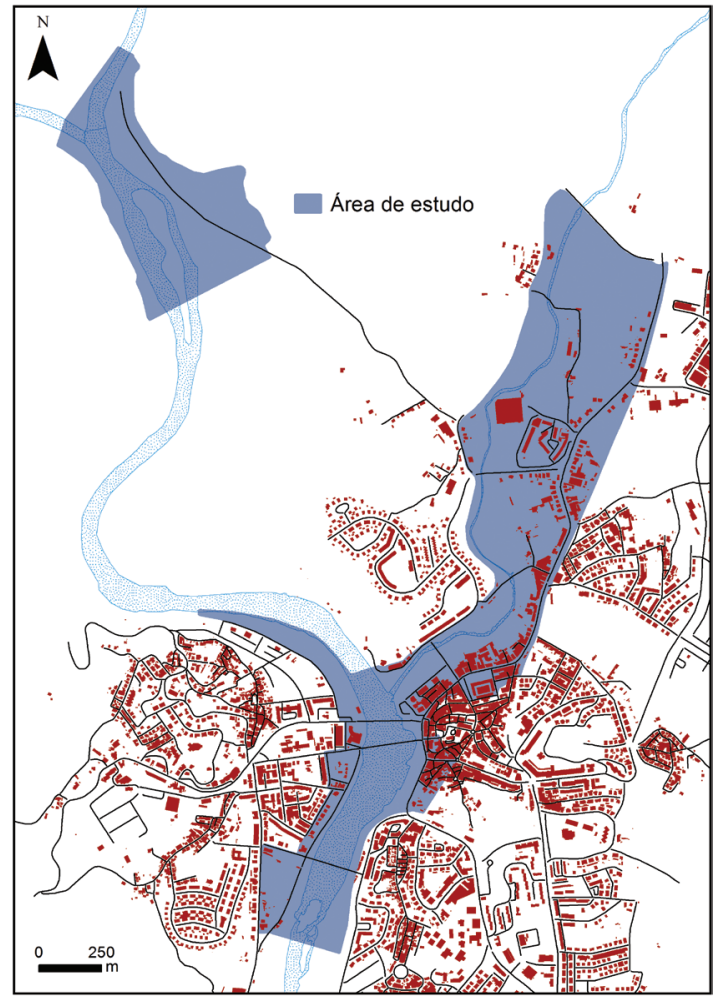

Fig. 3 - Área de estudo (Fonte: Adaptado das Folhas n. ${ }^{\circ} 76$ e 77, da Carta Militar de Portugal, 1/25000, IGeoE, 1995.

Fig. 3 - Study area (Source: Adapted from the pages $n .{ }^{\circ} 76 \mathrm{e}$ 77, Portugal Army Map, 1/25000, IGeoE, 1995).
Curiosamente, apesar de a população ter aumentado na freguesia de Mirandela, entre 1991 e 2011, a população residente na área de estudo apresentou a mesma evolução que a do concelho de Mirandela, tendo registado, entre 1991 e 2001, um aumento de 370 habitantes, decrescendo, mais tarde, entre 2001 e 2011, em 137 residentes. Apesar do decréscimo do número de habitantes que se registou entre 2001 e 2011, a taxa de variação foi positiva, na ordem dos 32,1\% (fig. 4-A). Do mesmo modo, o edificado apresentou uma situação idêntica, isto é, o seu valor aumentou, de 1991 para 2001, num total de 75 edifícios, tendo-se-lhe seguindo um pequeno decréscimo, entre 2001 e 2011, de apenas 6 edifícios (fig. 4-B).

Embora seja notório que a população residente na área do concelho de Mirandela decresceu, ao longo dos 30 anos (1981 a 2011), num total de 5029 habitantes, em contrapartida, a área da freguesia de Mirandela aumentou a sua população residente, tendo-se registado um acréscimo, ao longo de 20 anos, de 3663 habitantes (TABELA I). Este facto está, sobretudo, relacionado com os meios e recursos existentes na cidade de Mirandela, que têm a capacidade de atrair a população das áreas rurais circundantes. Discordante desta oscilação é a do número de edifícios que praticamente tem vindo sempre a aumentar, quer na área do concelho, quer na área da freguesia, embora na área de estudo, tal só se tenha verificado nos primeiros dez anos (1991 a 2001), quando 

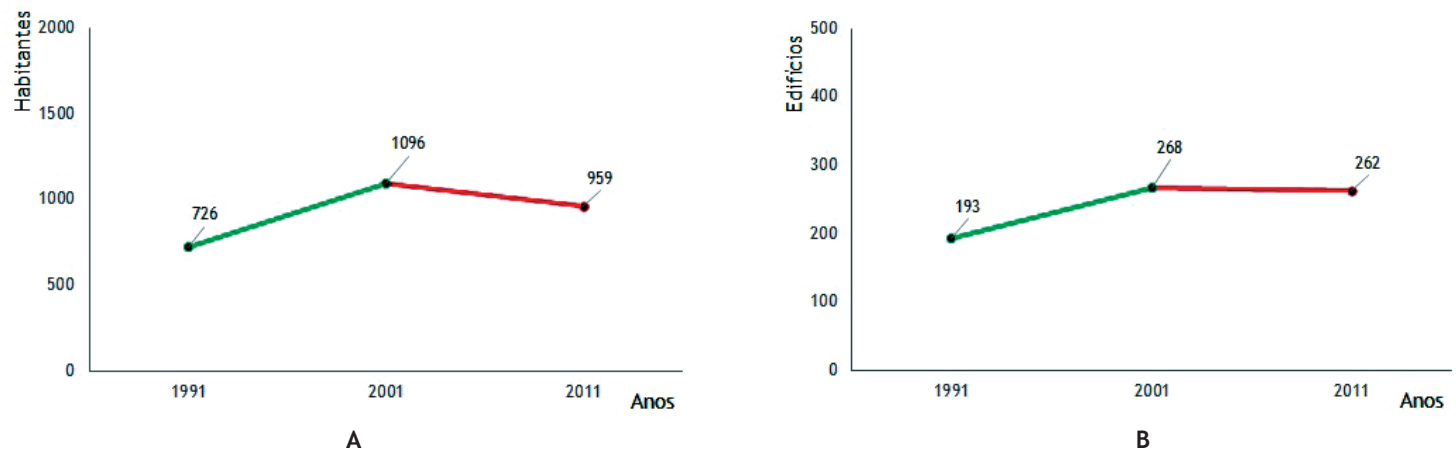

Fig. 4 - População residente (A) e número de edifícios (B) na área de estudo (Fonte dos dados: INE, 1991, 2001, 2011).

Fig. 4 - Resident population (A) and buildings (B) in study area (Data source: INE, 1991, 2001, 2011).

$T_{A B E L A}$ I - Evolução da população residente e do número de edifícios no concelho, freguesia e área de estudo de Mirandela.

TABLE I - Evolution of the resident population and buildings in Mirandela county, parish and study area.

\begin{tabular}{|r|r|r|r|r|r|r|}
\hline \multirow{2}{*}{ Anos } & \multicolumn{2}{|c|}{ Concelho } & \multicolumn{2}{c|}{ Freguesia } & \multicolumn{2}{c|}{ Área de estudo } \\
\cline { 2 - 7 } & População & \multicolumn{1}{|c|}{ Edifícios } & População & \multicolumn{1}{c|}{ Edifícios } & \multicolumn{1}{c|}{ População } & \multicolumn{1}{c|}{ Edifícios } \\
\hline 1981 & 28879 & 9018 & Sem dados & Sem dados & Sem dados & Sem dados \\
\hline 1991 & 25209 & 9957 & 8189 & 2006 & 726 & 193 \\
\hline 2001 & 25819 & 11369 & 11186 & 2765 & 1096 & 268 \\
\hline 2011 & 23850 & 11515 & 11852 & 3217 & 959 & 262 \\
\hline
\end{tabular}

Fonte dos dados/Source data: INE, 1981, 1991, 2001, 2011.

se assistiu a um ligeiro aumento de população residente e do número de edifícios, mas, depois, nos dez anos seguintes (2001 a 2011), seguiu-se uma tímida descida desses valores (TABELA I).

Tendo o INE disponibilizado, para os anos de 1991, 2001 e 2011, o número de edifícios e de população residente ao nível da subsecção estatística, decidiu-se efetuar a espacialização dos mesmos na área de estudo, tendo-se utilizando a mesma escala para os três anos ( 5 classes, com intervalo de 42 habitantes para a população residente, e também 5 classes, com um intervalo de 8 edifícios) e procedido à análise de cada um desses mapas e das modificações que neles ocorreram ao longo dos 20 anos.

Todavia, após se ter sobreposto a área de estudo às subsecções estatísticas, verificou-se que o limite de ambas não era coincidente e, por isso, para as subsecções que extravasavam os limites da área de estudo foi efetuado o cálculo da percentagem de representação na área de estudo e decidiu-se eliminar todas as subsecções estatísticas cuja percentagem fosse inferior a $10 \%$. Esta situação deve-se ao facto de as subsecções estatísticas representadas em menos de $10 \%$ na área de estudo não terem expressão na produção cartográfica. Posto isto, efetuou-se o cálculo da percentagem de representação de cada subsecção estatística na área de estudo e aplicou-se essa mesma percentagem ao número de habitantes e ao número de edifícios existentes na totalidade da subsecção estatística e sempre que o resultado obtido fosse inferior a um edifício, esse registo era logo eliminado, pois sem edifícios não há residentes. Deste modo também se explica a existência de espaços sem dados, que obviamente não aparecem representados na cartografia.

Assim, em 1991, a população total que residia na área de estudo, era de 726 habitantes, o que representava cerca de $2,8 \%$ da população residente no concelho de Mirandela e cerca de $8,8 \%$ da população residente na freguesia de Mirandela, sendo a sua densidade populacional de 440 habitantes $/ \mathrm{km}^{2}$. O local onde se encontrava o maior número de habitantes (153 habitantes) e o maior número de edifícios (31 edifícios), corresponde ao sector central da área de estudo, junto à foz da ribeira de Carvalhais, entre a sua margem esquerda e a rua da República e entre a atual rotunda de Luciano Cordeiro e o Estádio de Futebol de São Sebastião (fig. 5).

Em 2001, a população total que residia na área de estudo, era de 1096 habitantes, o que representava cerca de $4,2 \%$ da população residente na área do concelho de Mirandela e $9,7 \%$ da população residente na freguesia de Mirandela, sendo a sua densidade populacional de 664 habitantes $/ \mathrm{km}^{2}$. Tal como em 1991, dos 1096 habitantes e dos 265 edifícios existentes, 209 habitantes e 38 edifícios concentravam-se, sobretudo, no sector central da área de estudo, junto à foz da ribeira de Carvalhais, entre a sua margem esquerda e a rua da República, 


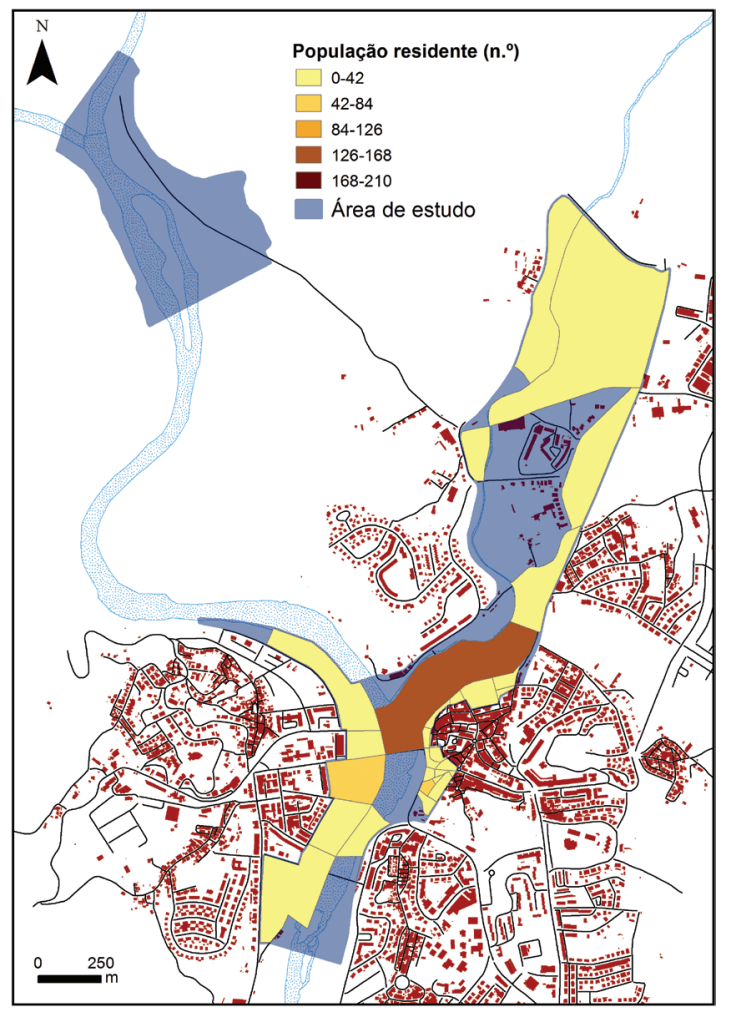

A

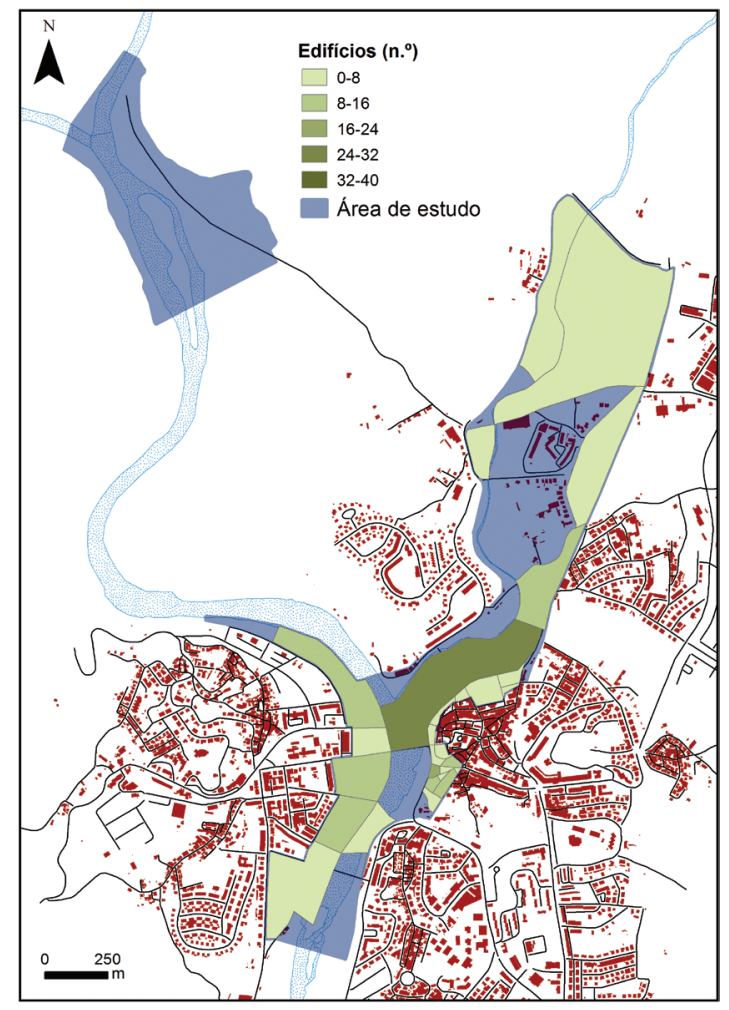

B

Fig. 5 - População residente (A) e número de edifícios (B) na área de estudo, em 1991 (Fonte: Adaptado de BGRE, INE, 1991 e das Folhas n. ${ }^{\circ} 76$ e 77 da Carta Militar de Portugal, 1/25000, IGeoE, 1995).

Fig. 5 - Resident population (A) and buildings (B) in the study area, in 1991 (Source: Adapted from BGRE, INE, 1991 and from the pages $n .^{\circ} 76$ and 77 of the Portugal Army Maps, 1/25000, IGeoE, 1995).

entre a atual rotunda de Luciano Cordeiro e o Estádio de Futebol de São Sebastião (fig. 6).

A configuração das subsecções estatísticas nos anos de 1991 e 2001 apresenta ligeiras diferenças pelo que se pode, por isso, efetuar a comparação da variação da localização da população residente e dos edifícios entre esses 10 anos. No entanto, porque a cartografia das subsecções estatísticas para o ano de 2011 é muito diferente das anteriores, essa análise comparativa não é fácil, tendo-se optado por efetuar, para este ano, uma análise em separado.

Assim, no ano de 2011, à semelhança dos anos de 1991 e 2001, a maior concentração de população correspondeu sensivelmente à mesma área. Em 2011, a população total que residia na área de estudo, era de 959 habitantes, o que representava $4,0 \%$ da população residente no concelho de Mirandela e $8,0 \%$ da população residente na freguesia de Mirandela, sendo a sua densidade populacional de 581 habitantes $/ \mathrm{km}^{2}$. Em 2011, a maior concentração de edifícios era, sobretudo, um pouco mais a norte do que nos anos de 1991 e 2001, localizando-se entre a Avenida da Galiza e a Rua da Ponte Romana e entre a margem esquerda da ribeira de Carvalhais e a Avenida das Comunidades Europeias (fig. 7), concentrando-se aí 26 edifícios.

\section{Variação da área impermeabilizada}

Sabendo-se que a impermeabilização do solo deriva do processo de urbanização, decidiu-se efetuar a cartografia da configuração da área urbana na área de estudo, isto é, foi criado um único polígono que abrange os edifícios e as rodovias existentes em dois momentos temporais. Assim, perante a disponibilidade de cartografia da cidade de Mirandela, a delimitação das áreas impermeabilizadas foi efetuada a partir de imagens raster, do ano de 1980, à escala 1/1000, e de ortofotomapas obtidos no ano de 2012.

Deste modo fica a conhecer-se o valor do aumento da área impermeabilizada e a forma como evoluiu o processo de urbanização, isto é, quais foram as áreas que se tornaram impermeáveis e que implicação é que isso poderá ter no momento em que se verificar uma inundação (fig. 8).

Em 1980 delimitaram-se cerca de 19,3 ha de área impermeabilizada, valor que, em 2012, subiu para 45,1 ha. Assim, pode dizer-se que a comparação dos dois mapas, permitiu validar a ideia de que nesses trinta e dois anos houve um aumento significativo das áreas impermeáveis, o qual correspondeu a um total de 25,8 ha, o que representa um aumento de $133,6 \%$ e que deriva do processo de urbanização da cidade de Mirandela. 


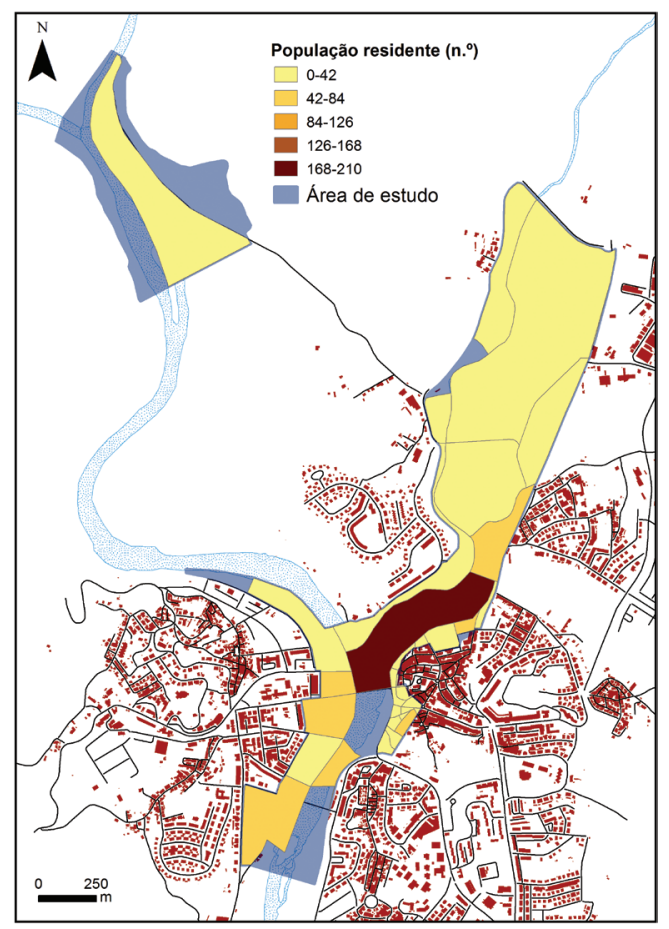

A

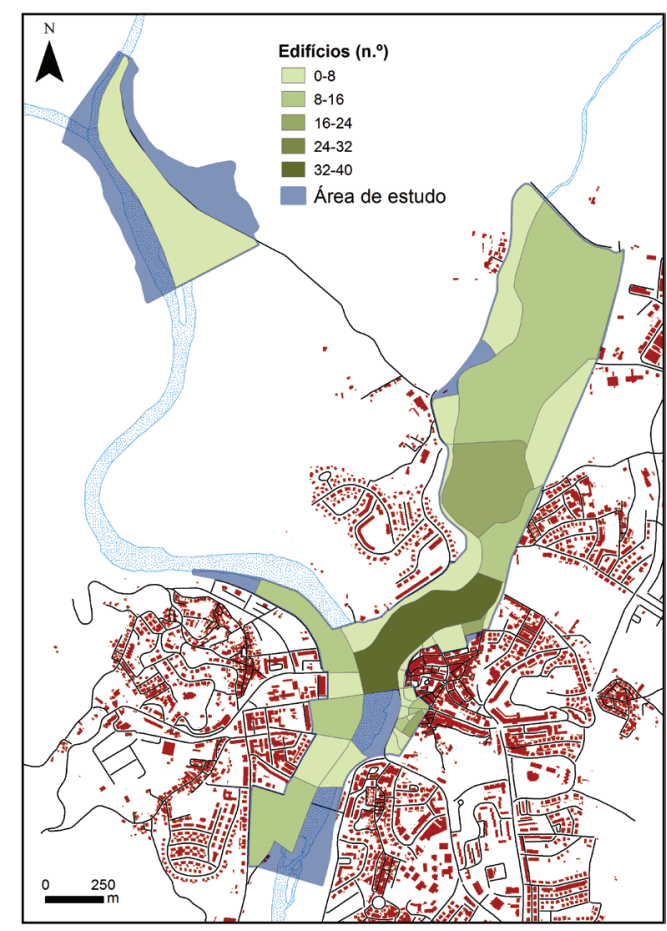

B

Fig. 6 - População residente (A) e número de edifícios (B) na área de estudo, em 2001 (Fonte: Adaptado de BGRI, INE, 2001 e das Folhas $n .^{\circ} 76$ e 77 da Carta Militar de Portugal, 1/25000, IGeoE, 1995).

Fig. 6 - Resident population and buildings in the study area, in 2001 (Source: Adapted from BGRE, INE, 2001 and from the pages $n .^{\circ}$ 76 and 77 of the Portugal Army Maps, 1/25000, IGeoE, 1995).

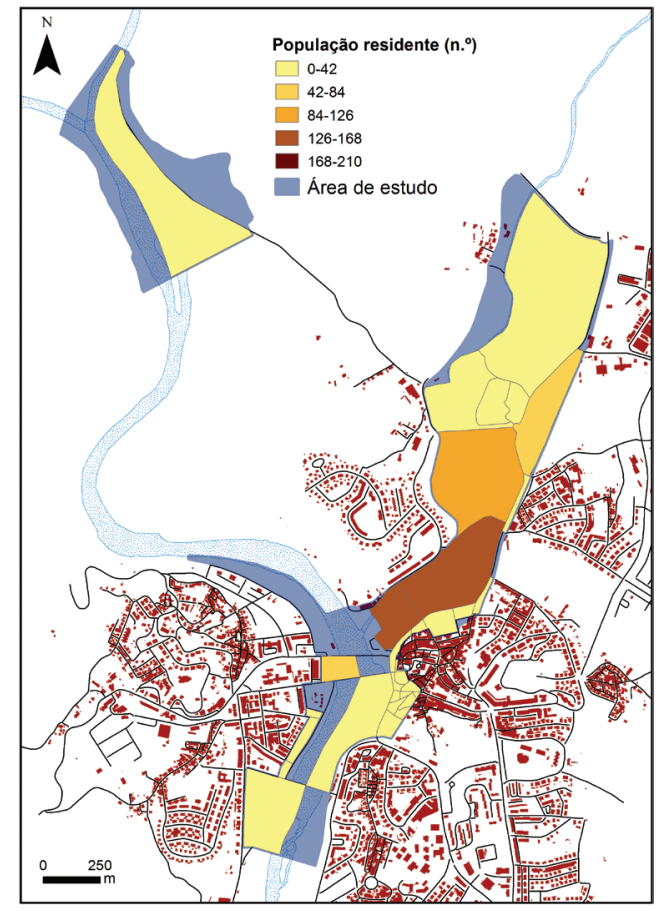

A

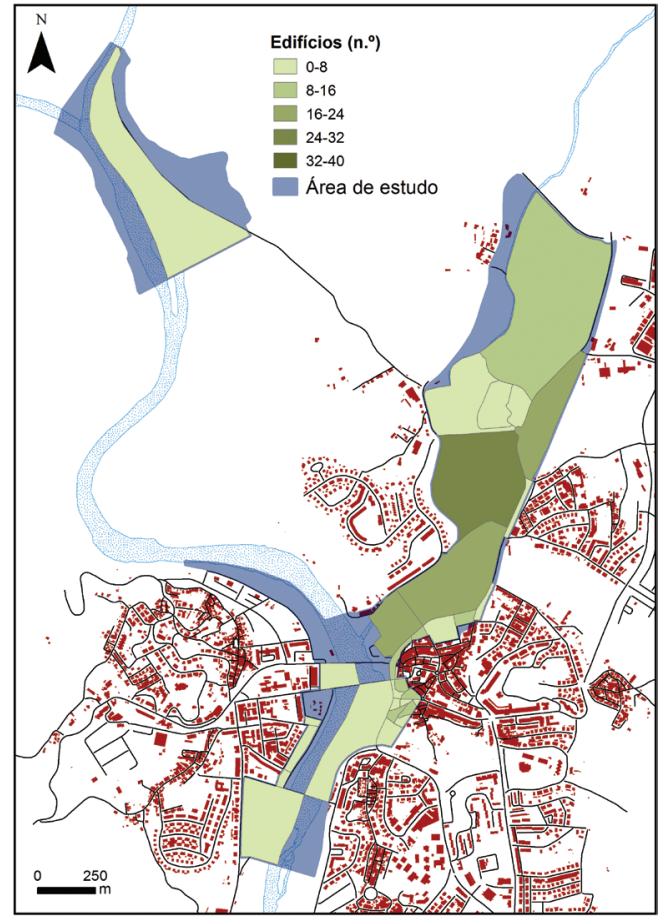

B

Fig. 7 - População residente (A) e número de edifícios (B) na área de estudo, em 2011 (Fonte: Adaptado de BGRI, INE, 2011 e da Folha n. ${ }^{\circ} 76$ e 77 da Carta Militar de Portugal, 1/25000, IGeoE, 1995).

Fig. 7 - Resident population (A) and buildings (B) in the study area, in 2011 ((Fonte: Adapted from BGRE, INE, 2011 and from the pages $n .^{\circ} 76$ and 77 of the Portugal Army Maps, 1/25000, IGeoE, 1995). 


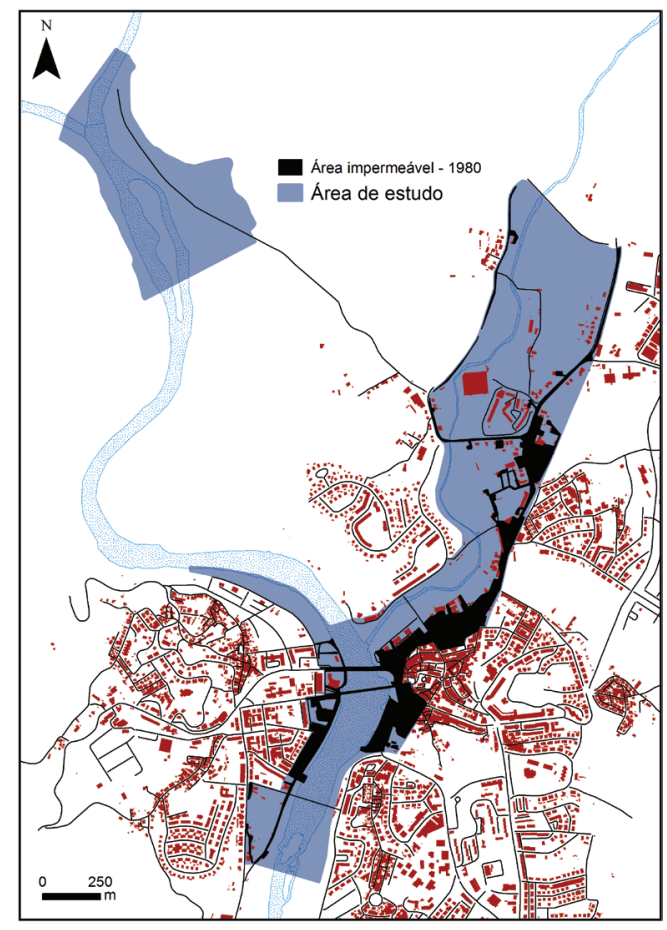

A

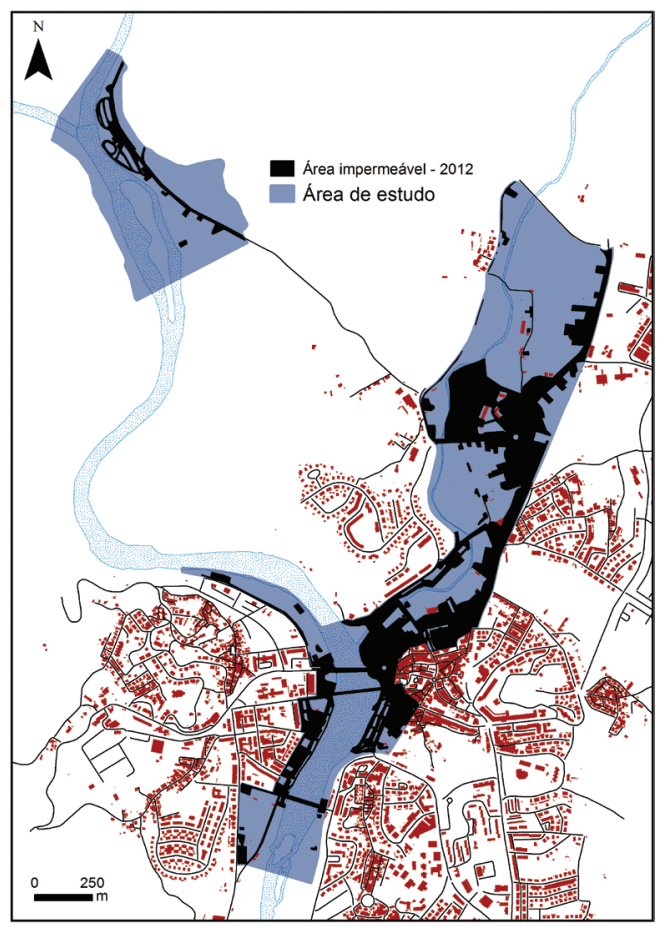

B

Fig. 8 - Áreas impermeabilizadas na área de estudo nos anos de 1980 (A) e 2012 (B) (Fonte: Adaptado de Cidade de Mirandela, 1/1000, DGT, 1980; Ortofotomapas, DGT, 2012; Folha n. ${ }^{0} 76$ e 77 da Carta Militar de Portugal, 1/25000, IGeoE, 1995)

Fig. 8 - Impermeable areas in the study area in 1980 (A) and 2012 (B) (Soure: Adapted fom Mirandela Municipalaty, 1/1000, DGT, 1980; Orthophotomaps, DGT, 2012; pages n. ${ }^{\circ} 76$ e 77 from the Portugal Army Maps, 1/25000, IGeoE, 1995).

\section{Conclusão}

Tendo-se verificado, ao longo de vinte anos (1991 a 2011) o aumento do número de habitantes e de edifícios na área de estudo e conhecendo-se a sua distribuição espacial pode concluir-se, que em conjunto com o consequente aumento das áreas impermeabilizadas, surgirão maiores dificuldades de infiltração da água proveniente de situações de cheia do rio Tua e que a existência de mais obstáculos, como por exemplo os edifícios que obstam ao rápido escoamento da água, irá facilitar a ocorrência de inundações cada vez mais violentas.

Posto isto, poderiam ser adotadas algumas medidas de mitigação na cidade, tais como a determinação de áreas com capacidade de retenção, onde poderia ser armazenada alguma água, passível de ser utilizada mais tarde, ou devolvida ao rio, após a situação de cheia. Outras medidas a tomar devem ser: informação dos interessados, no que respeita à aquisição de terrenos e casas situadas no leito de inundação; intervenção no território, tendo em conta o mapa de risco de inundação por forma a mitigar os danos; preparação de planos de seguros, com vista ao ressarcimento de valores afetados pelas inundações (Deltares, 2010, p. 57); relocalização de equipamentos implantados em áreas sujeitas a risco de inundação, por forma a evitar que se danifiquem; correção de declives (L. Lourenço, 1988, pp. 98-100), para impedir a inundação de determinadas áreas ou, pelo menos, para reduzir os danos por ela provocados; elaboração de um plano de emergência especial para situações de inundação, incluindo a marcação de rotas de evacuação e a implementação de um sistema de aviso e alerta (G. Saraiva, 1999, pp. 315-325).

Procedendo-se deste modo, estar-se-ia a contribuir para a proteção mais eficaz de pessoas, animais e bens patrimoniais existentes na cidade de Mirandela.

\section{Referências bibliográficas}

Costa, Francisco Silva (2009). O risco de inundação na cidade de Amarante (Norte de Portugal): Contributo metodológico para o seu estudo, Territorium, 16, Coimbra. Disponível em: http://www.uc.pt/fluc/nicif/riscos/Documentacao/ Territorium/T16_artg/T16art09.pdf.

Deltares (2010). Flood Risk Management, Delft.

DIREÇÃO-GERAL DOS RECURSOS E APROVEITAMENTOS HIDRÁULICOS (1984). Curso Internacional de Hidrologia Operativa, Vol. II, Lisboa.

DIRETIVA EUROPEIA n. ${ }^{\circ}$ 2007/60/CE, de 23 de outubro, transposta para o Decreto-Lei n. ${ }^{\circ} 115 / 2010$, de 22 de outubro. 


\section{RISCOS - Associação Portuguesa de Riscos, Prevenção e Segurança}

Gouveia, Maria; Lourenço, Luciano (2013). Manifestações do Risco de Inundação na cidade de Mirandela, Riscos Naturais, Antrópicos e Mistos, Homenagem ao Professor Doutor Fernando Rebelo, FLUC, Coimbra. Dispónivel em: http://www.uc.pt/fluc/depgeo/Publicacoes / livro_homenagem_FRebelo/501_514.

INSTITUTO NACIONAL DE ESTATíSTICA. Base Geográfica de Referenciação da Informação, 1991 e 2011.
Lourenço, Luciano (1988). Caderno de trabalhos práticos de geografia física, $1^{\mathrm{a}}$ parte, FLUC, Coimbra.

Ramos, Catarina (2009). Dinâmica fluvial e ordenamento do Território, CEG-UL, Lisboa.

Saraiva, Maria (1999). O rio como paisagem, Fundação Calouste Gulbenkian, Lisboa. 